\title{
Electron beam stimulated formation of CdS nanoparticles within calixarene Langmuir-Blodgett films
}

\author{
A. V. Nabok, A. K. Ray, and A. K. Hassan \\ Fibre-Optics \& Physical Electronics Research Laboratories, Electronic Research Group, \\ School of Engineering, Sheffield Hallam University, City Campus Pond Street, \\ Sheffield S1 1WB, United Kingdom
}

(Received 15 December 1999; accepted for publication 3 May 2000)

\begin{abstract}
Two possible types of cadmium sulphide ( $\mathrm{CdS}$ ) nanostructures can be formed within LangmuirBlodgett (LB) films of calixarene Cd salt as a result of exposure to $\mathrm{H}_{2} \mathrm{~S}$ gas: nanoclusters with the size of about $1.5 \mathrm{~nm}$ or two-dimensional planes with the thickness of about $1.7 \mathrm{~nm}$. Transmission electron microscopy and electron diffraction studies on calixarene/CdS LB films show that CdS particles are not present in the fresh samples at the beginning, but they are gradually formed under exposure to a high energy electron beam. A blueshift of the first exciton absorption band and an increase of the extinction coefficient, caused by exposure to $\mathrm{H}_{2} \mathrm{~S}$ gas, were found with UV-visible optical spectroscopy and surface plasmon resonance, respectively. (c) 2000 American Institute of Physics. [S0021-8979(00)07015-8]
\end{abstract}

\section{INTRODUCTION}

The main trend of microelectronics toward decreasing the feature size stimulates great interest in the development of nanoelectronic devices such as: resonance tunneling devices based on III-V semiconductor superlattices, ${ }^{1}$ silicon quantum dots, ${ }^{2}$ and single-electron tunneling transistors. ${ }^{3,4}$ The formation of nanosized elements requires some sophisticated and expensive technologies such as, molecular beam epitaxy (MBE), advanced x-ray and electron-beam lithography, scanning probe techniques, such as STM and AFM, etc., employing ultrahigh vacuum equipment and super clean environmental conditions. Alternatively, the wet technology has been adapted for producing nanosized elements due to recent achievements of colloid and organic chemistry and technology of thin organic films. ${ }^{5}$ A variety of colloid nanoparticles including metals ( $\mathrm{Au}, \mathrm{Ag}, \mathrm{Pt}, \mathrm{Pd})$, semiconductors $\left(\mathrm{CdS}, \mathrm{CuS}, \mathrm{CdSe}, \mathrm{PbSe}, \mathrm{PbTe}, \mathrm{TiO}_{2}\right.$ ), and insulators (ceramic, mica) have now become commercially available. ${ }^{5}$ These particles can be chemically modified and deposited by different techniques, such as Langmuir-Blodgett (LB) ${ }^{6}$ and polyelectrolyte self-assembly methods. ${ }^{7,8}$

A simple but elegant method of formation of II-VI semiconductor nanoparticles within LB film matrix has been proposed earlier by Barraud and co-workers ${ }^{9,10}$ with a view to forming two-dimensional (2D) semiconductor layers. By exposing LB films of fatty acid metal salt (cadmium stearate, for example) to $\mathrm{H}_{2} \mathrm{~S}$ gas, metal sulphide $(\mathrm{CdS})$ can be formed due to the following reaction:

$$
\begin{aligned}
& \left(\mathrm{CH}_{3}-\left(\mathrm{CH}_{2}\right)_{\mathrm{n}}-\mathrm{COO}\right)_{2} \mathrm{Cd}+\mathrm{H}_{2} \mathrm{~S} \\
& \quad=2\left(\mathrm{CH}_{3}-\left(\mathrm{CH}_{2}\right)_{\mathrm{n}}-\mathrm{COOH}\right)+\mathrm{CdS} .
\end{aligned}
$$

It was found that clusters of metal sulphides $(\mathrm{CdS}, \mathrm{PbS}$, $\mathrm{CuS}$ ) with the size of 3-5 nm were formed within the fatty acid LB film matrix due to molecular segregation. ${ }^{10-14} \mathrm{~A}$ similar idea has been exploited in our previous publications ${ }^{15-17}$ to form CdS nanoparticles within calix- arene LB films. It was suggested there that the presence of calixarene cavities restricts segregation of $\mathrm{CdS}$, and much smaller CdS particles were formed as a result. The size of $1.5 \pm 0.3 \mathrm{~nm}$ for $\mathrm{CdS}$ particles embedded into calixarene LB films was estimated from their UV-visible absorption spectra. ${ }^{15,16}$ However, both low angle x-ray diffraction ${ }^{16}$ and $\mathrm{AFM}^{17}$ experiments showed no respective changes in the diffraction pattern and morphology of calixarene LB films after exposure to $\mathrm{H}_{2} \mathrm{~S}$ gas. Transmission electron microscopy (TEM) showed no CdS particles on fresh samples during initial stages of inspection, but they grew later, possibly, stimulated by the electron beam. ${ }^{17}$

In the present work the formation of CdS nanoparticles in calixarene LB films was studied in situ using TEM and electron diffraction. Additional UV-visible optical spectroscopy and surface plasmon resonance (SPR) measurements were performed here in order to register changes of the optical parameters of calixarene LB films caused by the formation of CdS nanostructures. Possible applications are highlighted.

\section{EXPERIMENTAL DETAILS}

Tert-octyl calix[8]arene carboxylic acid, referred throughout the text as C[8]A (see chemical structures in Fig. 1) was chosen for LB film deposition. $0.5 \mathrm{mg} / \mathrm{ml}$ solution of $\mathrm{C}[8] \mathrm{A}$ compound in chloroform was spread onto Millipore water subphase containing $5 \times 10^{-4} \mathrm{M} \mathrm{CdCl}_{2}$ in order to form $\mathrm{Cd}$ salts in monolayers. The films were then transferred onto hydrophobic substrates at a constant surface pressure of $25 \mathrm{mN} / \mathrm{m}$ and at a deposition speed of $5 \mathrm{~mm} / \mathrm{min}$ for both down and up strokes. UV-visible absorption spectra of LB films transferred onto quartz slides were measured at room temperature on the same samples before and after $\mathrm{H}_{2} \mathrm{~S}$ treatment by using a UV4 UNICAM spectrophotometer. The spectra of CdS embedded into the film were then obtained by subtraction of the spectra measured before and after exposure 


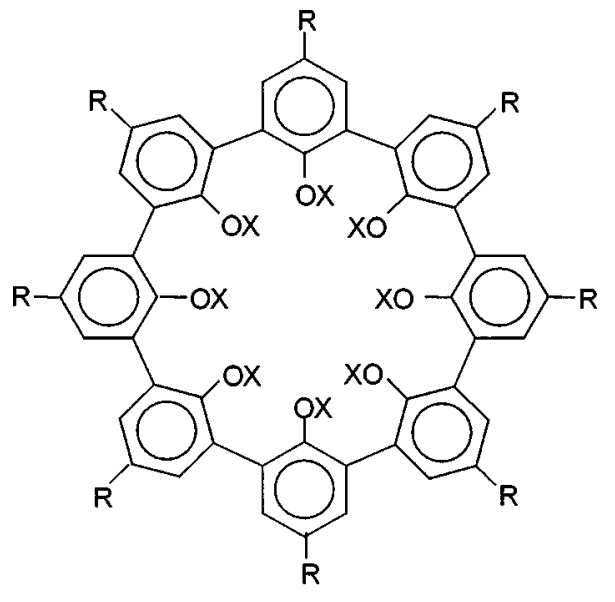

$\mathrm{X}=\mathrm{CH}_{2} \mathrm{COOH}, \quad \mathrm{R}=\mathrm{C}\left(\mathrm{CH}_{3}\right)_{2} \mathrm{CH}_{2} \mathrm{C}\left(\mathrm{CH}_{3}\right)_{3}$

FIG. 1. Chemical structures of calix[8]arene acid.

to $\mathrm{H}_{2} \mathrm{~S}$. Procedures of C[8]A LB film deposition, treatment of the samples with $\mathrm{H}_{2} \mathrm{~S}$, and optical characterization have been described in detail earlier. ${ }^{15}$

TEM and electron diffraction studies were performed on LB films deposited onto 300 mesh copper grids coated with amorphous carbon (Agar Scientific, UK). These measurements were performed using a Philips CM20 TEM operating at $200 \mathrm{keV}$ (electron wavelength of $0.00251 \mathrm{~nm}$ ). Electron diffraction patterns were recorded using an unfocused electron beam of about $0.5 \mu \mathrm{m}$ in diameter. In order to study the effect of the dose of electron irradiation, series of TEM pictures and diffraction patterns were taken at an interval of 5 min from the film exposure under the focused electron beam.

SPR measurements were carried out on C[8]A LB films transferred onto the $45 \mathrm{~nm}$ gold coated glass slides, using a Kretschmann type $\theta-2 \theta$ rotated stage experimental setup described previously. ${ }^{18}$ The samples were brought into optical contact with the semicylindrical prism using index-matching liquid. A $p$-polarized HeNe laser source $(\lambda=632.8 \mathrm{~nm})$ was used for the excitation of surface plasmons. The SPR curves

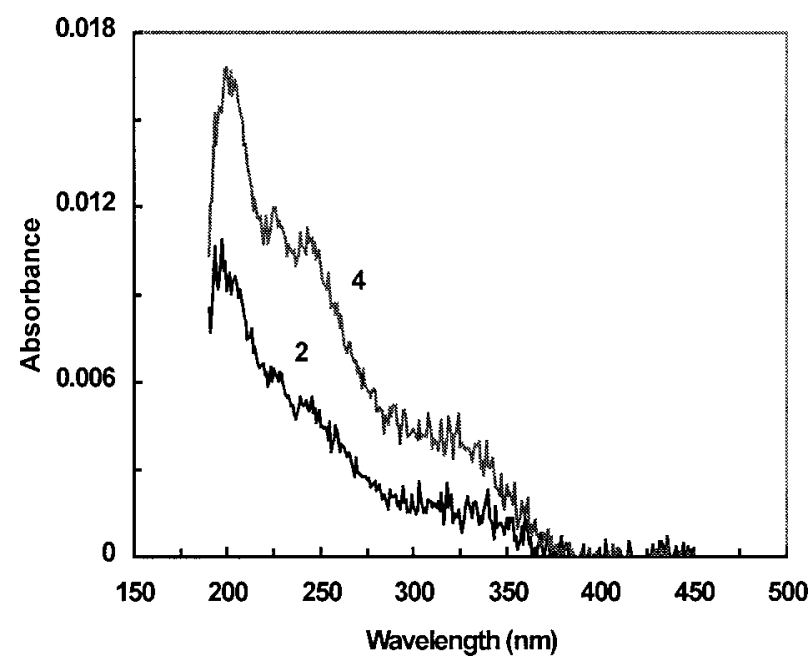

FIG. 2. UV-vis absorption spectra of CdS embedded into C[8]A LB films. Number of layers are shown next to respective curve.

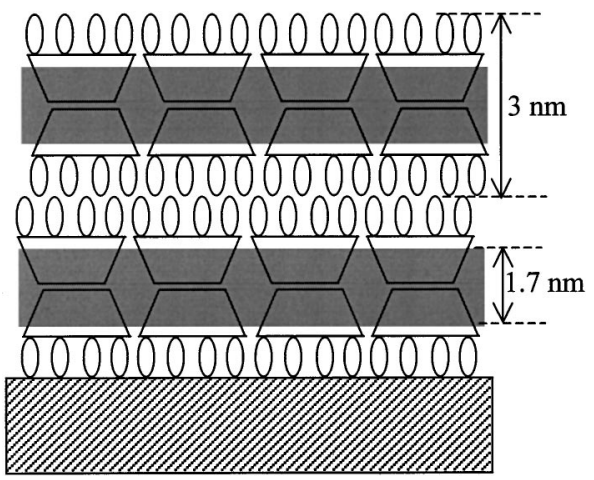

FIG. 3. A schematic model of 2D CdS planes within calixarene LB film: the thickness of the C[8]A bilayer is $3 \mathrm{~nm}$; the thickness of the CdS layer is 1.7 $\mathrm{nm}$.

were measured on the same samples before and after exposure to $\mathrm{H}_{2} \mathrm{~S}$ gas. Thickness $d$, refractive index $n$, and extinction coefficient $k$ of calixarene thin films were evaluated by fitting the experimental SPR curves to Fresnel's theory using a least-square technique. ${ }^{18,19}$

\section{RESULTS AND DISCUSSION}

Typical UV-visible absorption spectra of CdS imbedded into C[8]A LB films (two and four layers) are shown in Fig. 2. The absorption edge at $370 \mathrm{~nm}$ corresponds to the energy of $3.35 \mathrm{eV}$, which is much higher than that for bulk CdS $(2.4$ $\mathrm{eV})$. The observed blueshift of the absorption edge is believed to be caused by size quantization of exitons in $\mathrm{CdS}$ clusters. ${ }^{20}$ The size of semiconductor nanoclusters can be estimated from the method due to Ramakrishna ${ }^{21}$ based on direct calculations of the band structure of semiconductors using the method of pseudopotential. The size effect is investigated using the following expression for exciton energy in CdS spherical clusters with the radius $R:^{22,23}$

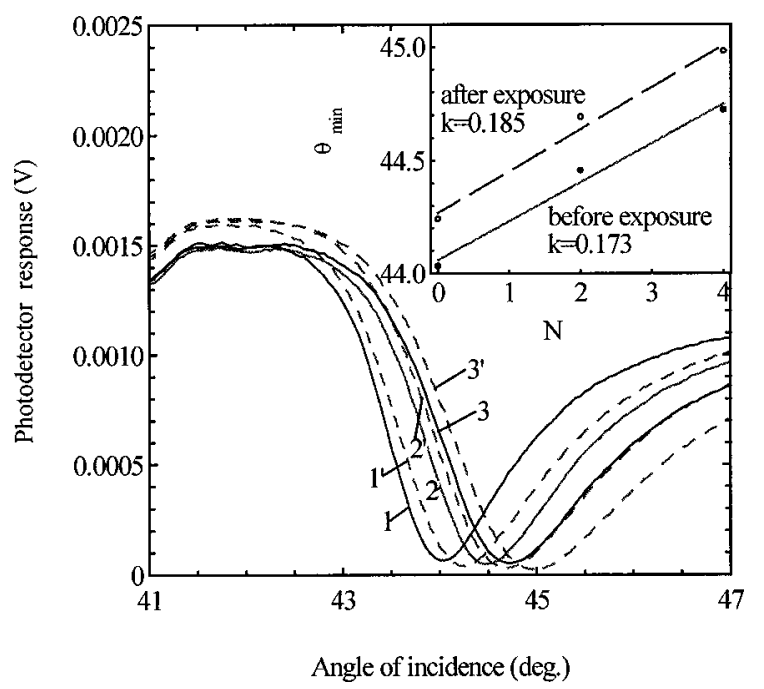

FIG. 4. Experimental SPR curves for $45 \mathrm{~nm}$ gold layer $\left(1,1^{\prime}\right)$ coated with C [8]A LB films of two layers $\left(2,2^{\prime}\right)$ and four layers $\left(3,3^{\prime}\right)$. Dashed line corresponds to SPR curves after exposure to $\mathrm{H}_{2} \mathrm{~S}$ gas. The inset shows dependencies of the position of the minimum of SPR curves on the number of LB layers. 
TABLE I. Optical parameters obtained by SPR fitting for bare gold and LB films.

\begin{tabular}{|c|c|c|c|c|c|c|c|c|c|}
\hline & \multicolumn{3}{|c|}{ Bare gold layer } & \multicolumn{3}{|c|}{ Two LB layers of C[4]A } & \multicolumn{3}{|c|}{ Four LB layers of $C[4] \mathrm{A}$} \\
\hline & $n$ & $k$ & $d(\mathrm{~nm})$ & $n$ & $k$ & $d(\mathrm{~nm})$ & $n$ & $k$ & $d(\mathrm{~nm})$ \\
\hline $\begin{array}{c}\text { Before } \\
\mathrm{H}_{2} \mathrm{~S}\end{array}$ & 0.188 & 3.337 & 45.03 & 1.46 & 0 & 1.58 & 1.46 & 0 & 3.09 \\
\hline $\begin{array}{c}\text { After } \\
\mathrm{H}_{2} \mathrm{~S}\end{array}$ & 0.279 & 3.248 & 47.28 & 1.47 & 0.244 & 1.58 & 1.45 & 0.115 & 3.09 \\
\hline
\end{tabular}

$$
E=E_{g}-\frac{1.786 e^{2}}{\varepsilon R}-0.248 E_{R},
$$

where $E_{g}$ is the band gap of the bulk material, and $\varepsilon$ is the dielectric constant of CdS. The second term in Eq. (1) represents Coulomb interaction between electrons and holes. The exciton binding energy is given in the form

$$
E_{R}=\frac{\mu e^{2}}{2 \varepsilon^{2} \hbar^{2}},
$$

where $\mu$ is the exciton reduced mass

$$
\left(\frac{1}{\mu}=\frac{1}{m_{e}^{*}}+\frac{1}{m_{h}^{*}}\right) .
$$

Using the $E(R)$ diagram from Ref. 21 a value of $1.5 \mathrm{~nm}$ was found for the diameter of $\mathrm{CdS}$ clusters embedded into $\mathrm{C}[8] \mathrm{A}$ LB film. This value is much smaller than 3-5 nm usually observed for CdS nanoparticles in fatty acid LB films. ${ }^{11-15}$ This leads to an inference that calixarene cavities limit the segregation of CdS particles within the film.

It can also be argued that $\mathrm{CdS}$ forms two-dimensional planes within each bilayer of calixarene LB films. In this case, energy spectra $E_{e, h}$ of electrons and holes within a layer of thickness $L_{Z}$ will be described as follows: ${ }^{24}$

$$
E_{e, h}=\frac{\hbar^{2}\left(k_{X}^{2}+k_{Y}^{2}\right)}{2 m_{e, h}^{*}}+\frac{\hbar^{2} \pi^{2}}{2 m_{e, h}^{*}} \frac{n_{z}^{2}}{L_{Z}^{2}} .
$$

Here the first term describes the motion of electrons and holes with the respective effective mass $m_{e}^{*}$ or $m_{h}^{*}$ within the $x, y$ plane, while the second term shows the series of levels of size quantization in the $z$ direction with the principal quantum number $n_{Z}$. The first exciton band in this case can be described as ${ }^{20}$

$$
E=E_{g}-E_{\mathrm{ex}}^{2 \mathrm{D}}+\frac{\pi^{2} \hbar^{2}}{2 \mu L_{Z}^{2}},
$$

where $E_{g}=2.425 \mathrm{eV}$ is the band gap for bulk $\mathrm{CdS}$ at room temperature, $E_{\mathrm{ex}}^{2 \mathrm{D}}$ is $2 \mathrm{D}$ exciton binding energy, which is four times larger than $E_{\mathrm{ex}}=0.028 \mathrm{eV}$ for bulk $\mathrm{CdS},{ }^{20}$ and $\mu$ $=0.125 m_{0}$. A value of $1.7 \mathrm{~nm}$ is obtained for $L_{Z}$, which is almost twice the cavity depth of calixarene. The formation of $\mathrm{CdS}$ planes can be postulated within each calixarene bilayer (see a scheme in Fig. 3), capturing CdS molecules in calixarene intrinsic cavities and, possibly, in the free space between molecules. This model is consistent with an earlier

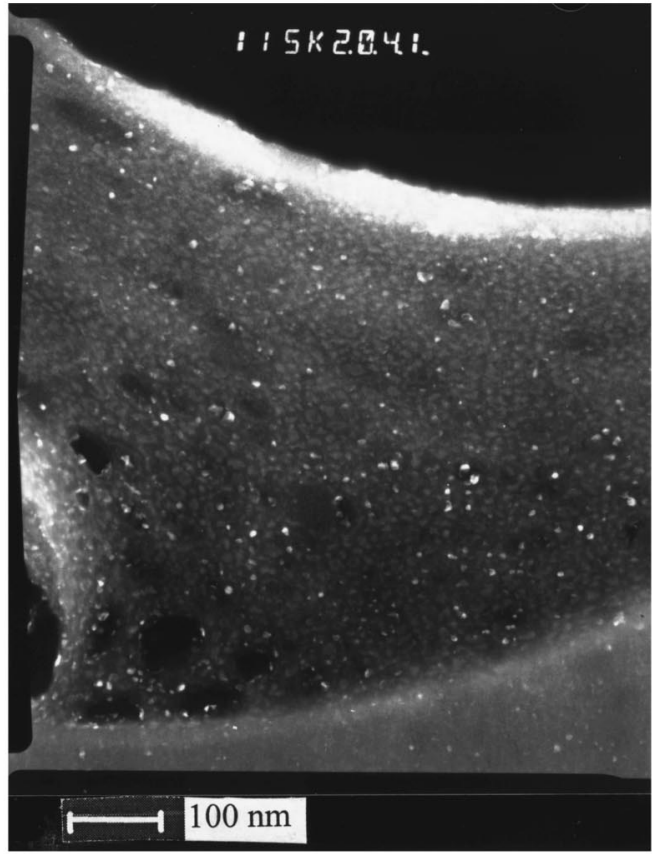

(a)

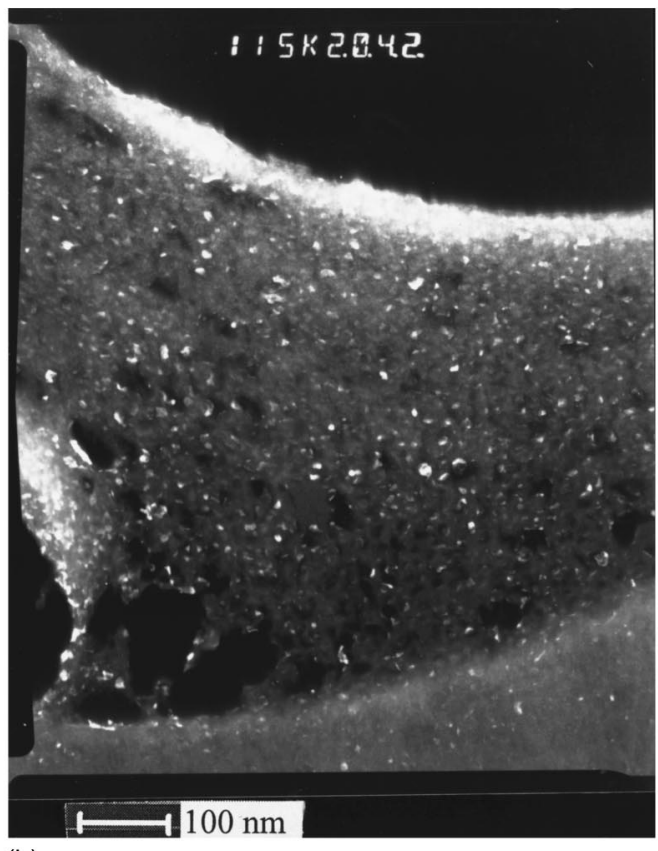

(b)

FIG. 5. TEM images of C[8]A LB film (ten layers) exposed to $\mathrm{H}_{2} \mathrm{~S}$ gas. Magnification is of 115000 . Photo (b) is taken 5 min after (a). 


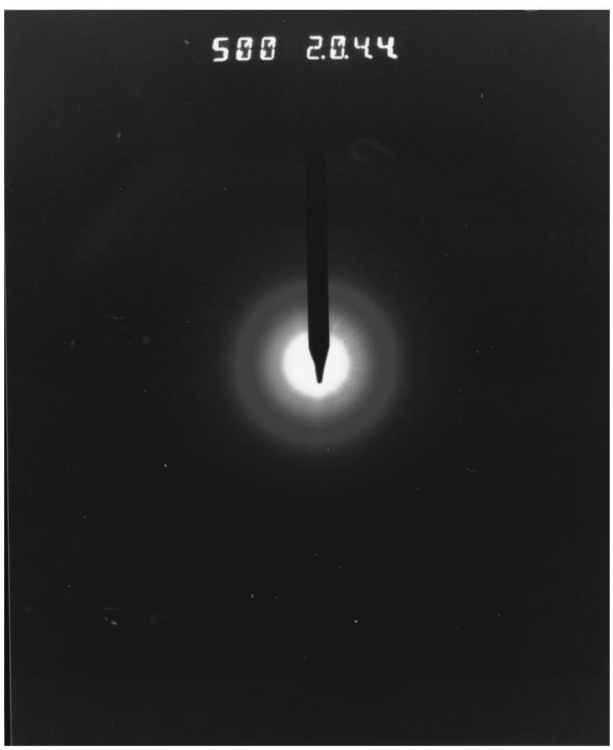

(a)

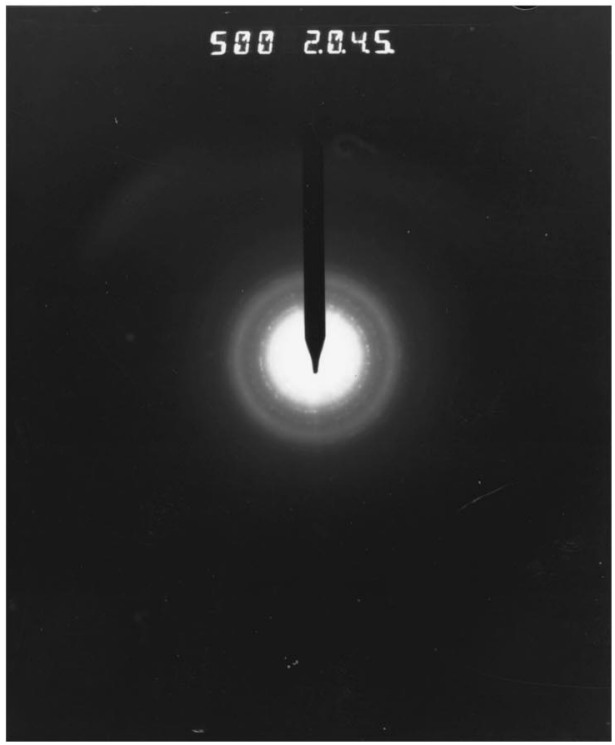

(b)

observation from x-ray and AFM studies that both the film structure and morphology have not changed after $\mathrm{H}_{2} \mathrm{~S}$ treatment. ${ }^{16,17}$

Figure 4 shows a subsequent shift in the minimum of the SPR curves to higher angles of incidence for two and four LB overlayers of $\mathrm{C}[8] \mathrm{A}$ molecules in respect to that for bare gold film. As seen from Fig. 4, the treatment of the samples in $\mathrm{H}_{2} \mathrm{~S}$ gas affects both the gold film and LB overlayers. The SPR curve for bare gold has undergone a small shift due to the formation of a monolayer of sulphur on the gold surface as a result of reaction with $\mathrm{H}_{2} \mathrm{~S}$ gas. It can be assumed that the gold surface covered with gas permeable calixarene LB films is affected by the same reaction. As shown by the inset to Fig. 4, the slope of the dependence $\theta_{\min }(N)$ is larger after the treatment with $\mathrm{H}_{2} \mathrm{~S}$ than before the treatment. This indicates that $\mathrm{H}_{2} \mathrm{~S}$ also affects the calixarene $\mathrm{LB}$ film due to the probable formation of $\mathrm{CdS}$ particles.

Calixarene matrix and $\mathrm{CdS}$ clusters are both virtually

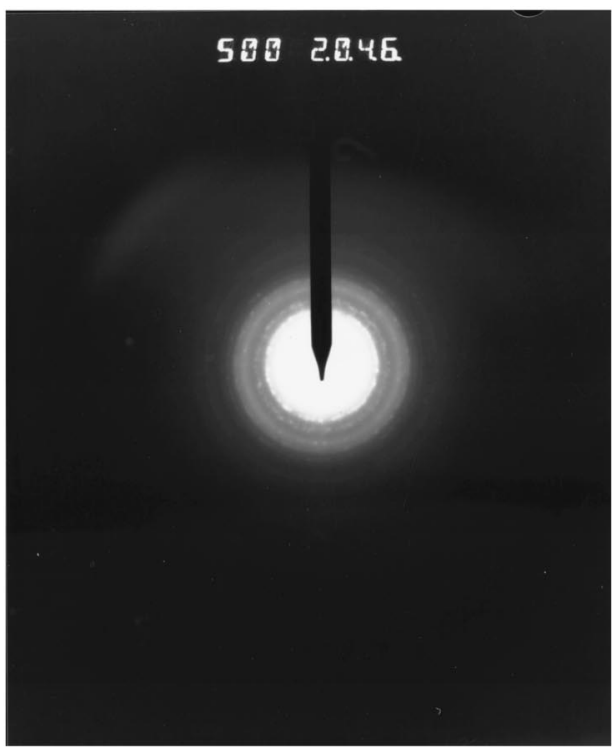

(c)

FIG. 6. Electron diffraction patterns measured on C[8]A LB film (ten layers) exposed to $\mathrm{H}_{2} \mathrm{~S}$ gas. Patterns (a), (b), and (c) correspond to subsequent 5 min irradiation with focused electron beam.

transparent at $633 \mathrm{~nm}$. In order to evaluate refractive index $n$ and film thickness $d$ simultaneously, ${ }^{25}$ values of $n=1.46$ and $d=1.5 \mathrm{~nm}$ per $\mathrm{C}[8] \mathrm{A}$ monolayer, previously obtained from ellipsometric measurements, ${ }^{16}$ were used as starting values for the theoretical fitting to SPR data. Since the C[8]A LB films before $\mathrm{H}_{2} \mathrm{~S}$ treatment were transparent at $633 \mathrm{~nm}, k$ $=0$ was postulated as a first guess value for the extinction coefficient. The obtained optical parameters for bare gold film and LB overlayers both before and after exposure to $\mathrm{H}_{2} \mathrm{~S}$ gas are summarized in Table I. The increase of extinction coefficient after exposure to $\mathrm{H}_{2} \mathrm{~S}$ gas may indicate the presence of semiconducting 2D planes of $\mathrm{CdS}$ within an insulator matrix, in which surface plasmon polaritons are thought to be excited. Similar results have been obtained from in situ SPR measurements during CdS formation within cadmium arachidate LB films. ${ }^{26}$

Figure 5 shows two TEM images which were taken at time intervals of $5 \mathrm{~min}$ on the same place of specimen under 
continuos exposure to the electron beam. The growth of particles in both size and number with increasing time of exposure to a focused electron beam is very apparent. The size of the particles varies from 7 to $15 \mathrm{~nm}$, which is much higher than that evaluated from the absorption spectra of the samples unexposed to an electron beam. It should also be pointed out that no particles were observed in the fresh samples of CdS/C[8]A LB films during initial stages of TEM experiments. This is in contrast to our previous TEM observation of CdS particles in stearic acid LB films, which appeared without stimulation by the electron beam. ${ }^{17}$

A set of three electron diffraction patterns of $\mathrm{CdS} / \mathrm{C}[8] \mathrm{A}$ LB film, taken at time intervals of 5 min, is shown in Fig. 6. They illustrate the transition from diffused rings for the fresh sample [Fig. 6(a)], corresponding to an amorphous carbon substrate, to spotty rings [Fig. 6(b)]. The rings become increasingly pronounced with the time of exposure [Fig. 6(c)]. These transformations in the diffraction pattern are believed to be caused by the growth of $\mathrm{CdS}$ clusters.

Values of spacing $D=0.226,0.16$, and $0.133 \mathrm{~nm}$ were evaluated from the diffraction pattern in Fig. 6(c) by using Bragg's formula 2D $\sin \varphi=n \lambda$. The lattice parameters $a_{0}$ can be calculated by comparison of the experimental $D$ values with $D_{h k l}$ spacing $^{27}$

$$
a_{0}=D_{h k l} \sqrt{h^{2}+k^{2} l^{2}},
$$

where $h, k$, and $l$ are Miller's indices for fcc zinc blende type lattice.

The last two values of 0.16 and $0.133 \mathrm{~nm}$ of spacing correspond most likely to (222) and (331) directions, respectively, and yield $a_{0}=0.567 \pm 0.012 \mathrm{~nm}$. The lattice parameter is less than a value of $0.583 \mathrm{~nm}$ for bulk CdS, which was predicted by Ramakhrishna's theory. ${ }^{21}$ The spacing of 0.226 $\mathrm{nm}$ is not close to any crystallographic direction in fcc CdS zinc blende lattice and may correspond to the forbidden (211) direction with $D_{h k l}=0.237 \mathrm{~nm}$. However, the structure of small CdS clusters may be sufficiently disturbed by the presence of calixarene matrix, and some other crystallographic directions become available. Knowing the area of $3.0 \mathrm{~nm}^{2}$ occupied by the $\mathrm{C}[8] \mathrm{A}$ molecule from $\Pi$-A isotherm measurements ${ }^{15}$ and the number of $\mathrm{CdS}$ molecules per $\mathrm{C}[8] \mathrm{A}$ unit of 2.85, obtained with XPS, ${ }^{15}$ one can estimate the initial average distance between CdS molecules in the LB monolayer as $1.025 \mathrm{~nm}$. This value is much higher than the obtained spacing of $0.567 \mathrm{~nm}$ in CdS clusters indicating the segregation of CdS caused by the electron beam.

\section{CONCLUSION REMARKS}

The observed blueshift of the main exciton absorption band ${ }^{15,16}$ can be interpreted in terms of the formation of either very small CdS nanoclusters with the size of about 1.5 $\mathrm{nm}$ or $2 \mathrm{D}$ CdS planes with a thickness of about $1.7 \mathrm{~nm}$ within each calixarene bilayer. The fact that $\mathrm{CdS}$ nanoparticles were not observed in our previous experiments with both $\mathrm{x}$-ray diffraction and $\mathrm{AFM}^{16,17}$ favors the second model. In the present study, SPR measurements of LB films of calixarene $\mathrm{Cd}$-salt show a sufficient increase in the extinction coefficient after exposure to $\mathrm{H}_{2} \mathrm{~S}$ gas, which indicates the presence of conductive (semiconductive) inclusions within the film. TEM and electron diffraction shows no CdS particles in fresh samples of CdS/C[8]A LB films, but they have appeared later under exposure to a focused electron beam. The segregation of 2D CdS planes and formation of $\mathrm{CdS}$ nanoparticles stimulated by the electron beam is the most likely mechanism of the observed behavior.

Therefore, we succeed with the formation of two kind CdS nanostructures: 2D CdS planes initially formed within calixarene LB films, which can be later transformed to nanoclusters due to exposure to the high energy electron beam. This opens the direction for further research work toward the development of novel nanoelectronic and optoelectronic devices. In the case of $1.5 \mathrm{~nm}$ II-VI semiconductor clusters, switching elements can be fabricated on the basis of singleelectron transistors ${ }^{3,4}$ with well resolved at room temperature staircase-like current-voltage $(I-V)$ characteristics. In contrast, superlattices consisting of 2D semiconducting plates may show electro-optical effect ${ }^{28}$ or some other nonlinear optical properties. Moreover, Little's type high-temperature superconductivity ${ }^{29}$ is expected for a single $2 \mathrm{D}$ semiconductor plane between two thin polar insulating layers. Further experiments are being undertaken to investigate mechanisms of planar conductivity and single-electron transfer across the films.

\section{ACKNOWLEDGMENTS}

The authors wish to thank Dr. F. Davis for synthesis of calixarene compounds, Professor J. Titchmarsh for his help with TEM measurements, and Dr. T. Richardson for fruitful discussion.

${ }^{1}$ F. Capasso, K. Mohammed, and A. Y. Cho, IEEE J. Quantum Electron. QE-2, 1853 (1986).

${ }^{2}$ M. Fukuda, N. Nakagava, S. Miyazaki, and M. Hirose, Appl. Phys. Lett. 70, 2291 (1997)

${ }^{3}$ E. S. Snow, P. M. Campbell, R. W. Rendell, F. A. Buot, D. Park, C. R. K. Marian, and R. Magno, Semicond. Sci. Technol. 13, A75 (1998).

${ }^{4}$ H. Weller, Angew. Chem. Int. Ed. Engl. 37, 1658 (1998).

${ }^{5}$ J. H. Fendler and F. C. Meldrum, Adv. Mater. 7, 607 (1995).

${ }^{6}$ N. A. Kotov, F. C. Meldrum, C. Wu, and J. H. Fendler, Phys. Chem. 99, 2735 (1994)

${ }^{7}$ Yu. M. Lvov and G. Decher, Crystallogr. Rep. 39, 628 (1994).

${ }^{8}$ N. A. Kotov, I. Dekany, and J. H. Fendler, J. Phys. Chem. 99, 13065 (1995).

${ }^{9}$ A. Rauadel-Teixier, J. Leloup, and A. Barraud, Mol. Cryst. Liq. Cryst. 134, 695 (1986).

${ }^{10}$ H. Weller, H. M. Schmidt, and U. Koch, Chem. Phys. Lett. 152, 265 (1988).

${ }^{11}$ E. S. Smotkin, C. Lee, A. J. Bard, A. Campion, M. A. Fox, T. E. Mallouk, S. E. Webber, and J. M. White, Chem. Phys. Lett. 152, 265 (1988).

${ }^{12}$ J. Leloup, A. Ruadel-Teixier, and A. Barraud, Thin Solid Films 210/211, 407 (1992).

${ }^{13}$ X. G. Peng, R. Lu, Y. Y. Zhao, L. H. Qu, H. Y. Chen, and T. J. Li, J. Phys. Chem. 98, 359 (1994).

${ }^{14}$ S. Ogava, F. R. F. Fan, and A. Bard, J. Phys. Chem. 99, 11182 (1995).

${ }^{15}$ A. V. Nabok, T. Richardson, F. Davis, and C. J. M. Stirling, Langmuir 13, 3198 (1997).

${ }^{16}$ A. V. Nabok, T. Richardson, C. McCartney, N. Cowlam, F. Davis, C. J. M. Stirling, A. K. Ray, V. Gassem, and A. Gibaud, Thin Solid Films 327-329, 510 (1998).

${ }^{17}$ A. V. Nabok, A. K. Ray, A. K. Hassan, J. M. Titchmarsh, F. Davis, T. Richardson, A. Starovoitov, and S. Bayliss, Mater. Sci. Eng., C 8-9, 171 (1999). 
${ }^{18}$ A. K. Ray, A. K. Hassan, M. R. Saatchi, and M. J. Cook, Philos. Mag. 76, 961 (1997).

${ }^{19}$ A. V. Nabok, A. K. Hassan, A. K. Ray, O. Omar, and V. I. Kalchenko, Sens. Actuators B 45, 115 (1997).

${ }^{20}$ A. D. Yoffe, Adv. Phys. 42, 173 (1993).

${ }^{21}$ M. V. Ramakhrishna and R. A. Frisher, J. Chem. Phys. 95, 8309 (1991).

${ }^{22}$ L. E. Brus, J. Chem. Phys. 90, 2555 (1986).

${ }^{23}$ Y. Kayanuma, Phys. Rev. B 38, 9797 (1988).

${ }^{24}$ S. D. Smith, Optoelectronic Devices (Prentice Hall, Englewood Cliffs, NJ, 1995), p. 67.
${ }^{25}$ H. E. de Bruijn, B. S. F. Altenberg, R. P. H. Kooyman, and J. Greve, Opt. Commun. 82, 425 (1991).

${ }^{26}$ N. J. Geddes, R. S. Urquhart, D. N. Furlong, C. R. Lawrence, K. Tanaka, and Y. Okahata, J. Phys. Chem. 97, 13767 (1993).

${ }^{27}$ W. F. DeJong, General Crystallography (W. H. Freemam \& Co, San Francisco, CA, 1959), p. 149.

${ }^{28}$ C. Weisbuch and B. Vinter, Quantum Semiconductor Structures (Academic, New York, 1991), p. 252.

${ }^{29}$ W. A. Little, in Novel Superconductivity, edited by S. A. Wolf and V. Z. Kresin (Plenum, New York, 1987), p. 341. 